\title{
Treatment of candiduria with micafungin: A case series
}

\author{
Danny Lagrotteria MD FRCPC ${ }^{1}$, Coleman Rotstein MD FRCPC ${ }^{1}$, Christine H Lee MD FRCPC ${ }^{1,2,3}$
}

\section{Lagrotteria, C Rotstein, CH Lee. Treatment of candiduria with micafungin: A case series. Can J Infect Dis Med Microbiol 2007;18(2):149-150.}

There has been a gradual increase in the incidence of non-Candida albicans-related nosocomial infections. Candida glabrata urinary tract infections have increased in frequency, and treating these infections can be difficult because the organism may be resistant to fluconazole. A newer antifungal agent, micafungin, which belongs in the class of echinocandins, provides an alternative and effective therapy against $\mathrm{C}$ glabrata. The present report describes three cases of $\mathrm{C}$ glabrataassociated urinary tract infections successfully treated with micafungin. To the authors' knowledge, this is the first report of successful treatment of $\mathrm{C}$ glabrata and azole-resistant $\mathrm{C}$ albicans-associated urinary tract infection with an echinocandin.

\section{Traitement de la candidurie à la micafungine : série de cas}

Il y a eu une augmentation graduelle des infections nosocomiales à d'autres germes que Candida albicans au fil du temps. La fréquence des infections urinaires à Candida glabrata est plus élevée qu'avant et il peut être difficile de traiter ces infections parce que le micro-organisme en cause peut se montrer résistant au fluconazole. Un nouveau médicament antifongique, la micafungine, qui appartient à la classe des échinocandines, offre un traitement de rechange efficace contre $\mathrm{C}$ glabrata. Le présent rapport fait état de trois cas d'infection urinaire à $\mathrm{C}$ glabrata, traités avec succès à la micafungine. D'après les auteurs, il s'agirait là du premier rapport de traitement réussi d'infections urinaires à $\mathrm{C}$ glabrata et à $\mathrm{C}$ albicans résistant aux azoles, à l'aide d'une échinocandine.

Key Words: Candiduria; Echinocandins

$\mathrm{T}$ he causative species producing candiduria in adults are similar in most studies. Candida albicans accounts for $50 \%$ to $70 \%$ of all Candida-related urinary isolates, followed by Candida glabrata, which comprises $20 \%$ of isolates, and Candida tropicalis, which is the third most common species (1). There has been a steady increase in the incidence of nonalbicans strains producing nosocomial infections (2-4). Notably, C glabrata candiduria has increased in frequency following the widespread and increased use of immunosuppressive agents and broad-spectrum antifungal agents (5). C glabrata in the urine is of special importance due to its increased resistance to fluconazole $(6,7)$. Furthermore, fluconazole use has been associated with $\mathrm{C}$ glabrata candiduria but not with $\mathrm{C}$ albicans candiduria. No other specific epidemiological risk factors for $\mathrm{C}$ glabrata urinary tract infection have been reported. Diabetes mellitus, indwelling bladder catheter, female sex and the use of antibacterial agents have been risk factors identified for both C glabrata and C albicans candiduria (8).

The echinocandins are a class of antifungal agents that provide an alternative and effective therapy against $\mathrm{C}$ glabrata. Like other echinocandins, micafungin (Mycamine, Astellas Pharma, Inc, USA) inhibits glucan synthesis, an enzyme required for the synthesis of a major fungal cell wall component, 1-3-beta D-glucan, and interferes with fungal cell wall synthesis (9). Although metabolized in the liver, micafungin may be useful in the treatment of candiduria. The present report describes our experience with micafungin in the treatment of persistent urinary tract infections associated with C glabrata and fluconazole-resistant $\mathrm{C}$ albicans.

\section{Case 1}

\section{CASE PRESENTATIONS}

A 39-year-old woman with type 1 diabetes mellitus developed urinary dysuria, frequency, urgency and pelvic discomfort shortly after renal transplantation. Her immunosuppressive therapy included mycophenolate mofetil, tacrolimus and prednisone. Although kidney and bladder ultrasound did not show evidence of obstruction or fungal ball, a urine culture produced more than $100 \times 10^{6}$ colony-forming units (CFU)/L of C glabrata, for which she received a six-week course of fluconazole $200 \mathrm{mg}$ daily (orally).

Three months after transplantation, the symptoms of cystitis recurred, without systemic features. Klebsiella pneumoniae and C glabrata were cultured in urine. Despite treatment with oral ciprofloxacin $250 \mathrm{mg}$ twice daily for 14 days, the patient remained symptomatic. She then received a 10 -day course of intravenous ceftriaxone $1 \mathrm{~g}$ daily, followed by 14 days of oral cefixime $400 \mathrm{mg}$ once daily. Following this treatment, there was still no resolution in her symptoms.

${ }^{1}$ Department of Medicine, McMaster University; ${ }^{2}$ Hamilton Regional Laboratory Medicine Program; ${ }^{3}$ Department of Pathology and Molecular Medicine, McMaster University, Hamilton, Ontario

Correspondence: Dr Christine H Lee, Department of Pathology and Molecular Medicine, McMaster University, St Joseph's Healthcare,

50 Charlton Avenue East, Hamilton, Ontario L8N 4A6. Telephone 905-521-6021, fax 905-521-6083, e-mail clee@mcmaster.ca Received for publication May 10, 2006. Accepted November 16, 2006 
Urine cultures were repeated and $\mathrm{C}$ glabrata was resistant to fluconazole (minimal inhibitory concentration [MIC] $256 \mu \mathrm{g} / \mathrm{mL}$ ) and itraconazole (MIC greater than $16 \mu \mathrm{g} / \mathrm{mL}$ ), but sensitive to 5-flucytosine (MIC less than $0.03 \mu \mathrm{g} / \mathrm{mL}$ ) and amphotericin B (MIC $0.25 \mu \mathrm{g} / \mathrm{mL}$ ). At this time, a bladder ultrasound demonstrated a fungal ball, which was removed by cystoscopy.

Due to residual symptoms of cystitis, a urine culture was sent seven days following the procedure. It demonstrated more than $100 \times 10^{6} \mathrm{CFU} / \mathrm{L}$ of $\mathrm{C}$ glabrata. The patient received a 14-day course of intravenous micafungin $50 \mathrm{mg}$ daily. A complete resolution in her symptoms ensued, and her energy level and appetite returned to baseline. A urine culture performed seven and 90 days after the last micafungin dose revealed no significant growth. Her tacrolimus level remained within the therapeutic range at $6.1 \mathrm{ng} / \mathrm{mL}$ to $10.1 \mathrm{ng} / \mathrm{mL}$ (reference trough therapeutic range $5 \mathrm{ng} / \mathrm{mL}$ to $15 \mathrm{ng} / \mathrm{mL}$ ).

\section{Case 2}

A 75-year-old woman who had a longstanding history of primary Sjögren's syndrome with associated cutaneous vasculitis, renal insufficiency and pulmonary hypertension presented with a two-month history of malodorous and cloudy urine. She was otherwise asymptomatic. She recently had received a seven-day course of cloxacillin for recurrent pyoderma gangrenosum and associated cellulitis. Her medications included azathioprine and prednisone. No physical findings were evident. More than $100 \times 10^{6} \mathrm{CFU} / \mathrm{L}$ of $\mathrm{C}$ glabrata were identified in two urine cultures. The patient was treated with a 14-day course of intravenous micafungin $50 \mathrm{mg}$ daily, after which her symptoms resolved. Repeat urine cultures at one and 24 months after completion of micafungin therapy revealed no significant growth.

\section{Case 3}

A 43-year-old man with a history of glomerulonephritis, aortic valve replacement and three renal transplants was seen for the management of persistent candiduria. Following his third transplant in 1998, he had taken ciprofloxacin $500 \mathrm{mg}$ once daily for recurrent bacteriuria and multiple courses of oral fluconazole for persistent candiduria. He was otherwise asymptomatic. There were no fevers, chills or night sweats. His other medications included prednisone $10 \mathrm{mg}$ once daily, mycophenolate mofetil $750 \mathrm{mg}$ twice daily, tacrolimus $1 \mathrm{mg}$ twice daily, amlodipine $10 \mathrm{mg}$ once daily, ramipril $1.25 \mathrm{mg}$ once daily and coumadin $2 \mathrm{mg}$ once daily, as well as an albuterol inhaler and acetaminophen or oxycodone as needed.

Urine cultures persistently revealed more than $100 \times 10^{6} \mathrm{CFU} / \mathrm{L}$ of $\mathrm{C}$ albicans resistant to fluconazole (MIC $256 \mu \mathrm{g} / \mathrm{mL}$ ). Following a three-week treatment course with intravenous micafungin, the results of the laboratory investigations were all within normal range. His tacrolimus level remained within the therapeutic range at $7.1 \mathrm{ng} / \mathrm{mL}$ to $12.1 \mathrm{ng} / \mathrm{mL}$. At one and three months following the treatment, urine cultures showed no growth.

\section{DISCUSSION}

Candiduria can be treated with amphotericin B bladder irrigation, provided there is no upper tract infection; it may also be effectively treated with systemic amphotericin B or fluconazole (10). However, given the adverse effects of amphotericin B and reduced susceptibility to fluconazole, an alternative to these agents is a valuable addition to existing treatment options.

Micafungin has a broad spectrum of activity against Candida species, including azole-resistant C albicans (11). However, like other echinocandins, it is less active against Candida parapsilosis (12).

Micafungin possesses a minimal side effect profile and low potential for drug interactions. Moreover, clearance of micafungin is not renal dependent, and the dosage does not have to be adjusted in patients with renal impairment.

\section{CONCLUSION}

The present case reports provide new data on the use of echinocandins such as micafungin for the treatment of fungal urinary tract infections. Thus, echinocandins such as micafungin may prove to be effective and safe alternatives for the treatment of $\mathrm{C}$ glabrata and other less susceptible strains that produce candiduria (10).

\section{REFERENCES}

1. Kauffman CA, Vazquez JA, Sobel JD. Prospective multicenter surveillance study of funguria in hospitalized patients. The National Institute for Allergy and Infectious Diseases (NIAID) Mycoses Study Group. Clin Infect Dis 2000;30:14-8

2. Trick WE, Fridkin SK, Edwards JR, Hajjeh RA, Gaynes RP; National Nosocomial Infections Surveillance System Hospitals. Secular trend of hospital-acquired candidemia among intensive care unit patients in the United States during 1989-1999. Clin Infect Dis 2002;35:627-30.

3. Fidel PL, Vazquez JA, Sobel JD. Candida glabrata: Review of epidemiology, pathogenesis, and clinical disease with comparison to C. albicans. Clin Microbiol Rev 1999;12:80-96.

4. Beck-Sague C, Jarvis WR. Secular trends in the epidemiology of nosocomial fungal infections in the United States, 1980-1990. National Nosocomial Infections Surveillance System. J Infect Dis 1993;167:1247-51.

5. Rivett AG, Perry JA, Cohen J. Urinary candidiasis: A prospective study in hospitalized patients. Urol Res 1986;14:183-6.

6. Hithcock CA, Pye GW, Troke PF, Johnson EM, Warnock DW. Fluconazole resistance in Candida glabrata. Antimicrob Agents Chemother 1993;37:1962-5.

7. Baran J Jr, Klauber E, Barczak J, Riederer K, Khatib R. Trends in antifungal susceptibility among Candida sp. urinary isolates from 1994 and 1998. J Clin Microbiol 2000;38:870-1.

8. Harris AD, Castro J, Sheppard DC, Carmeli Y, Samore MH. Risk factors for nosocomial candiduria due to Candida glabrata and Candida albicans. Clin Infect Dis 1999;29:926-8.

9. Kurtz MB, Abruzzo G, Flattery A, et al. Characterization of echinocandin-resistant mutants of Candida albicans: Genetic, biochemical, and virulence studies. Infect Immun 1996;64:3244-51.

10. Anaissie EJ, Darouiche RO, Abi-Said D, et al. Management of invasive candidal infections: Results of a prospective, randomized, multicenter study of fluconazole versus amphotericin B and review of the literature. Clin Infect Dis 1996;23:964-72.

11. Maki K, Morishita Y, Iguchi Y, et al. In vitro antifungal activity of FK463, a novel water-soluble echinocandin-like lipopeptide. 38th Interscience Conference on Antimicrobial Agents and Chemotherapy, 1998 (Abstract F-141).

12. Ikeda F, Wakai Y, Matsumoto S, et al. Efficacy of FK463, a new lipopeptide antifungal agent, in mouse models of disseminated candidiasis and aspergillosis. Antimicrob Agents Chemother 2000;44:614-8 


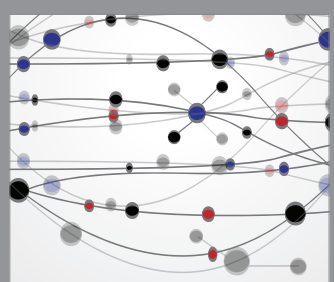

The Scientific World Journal
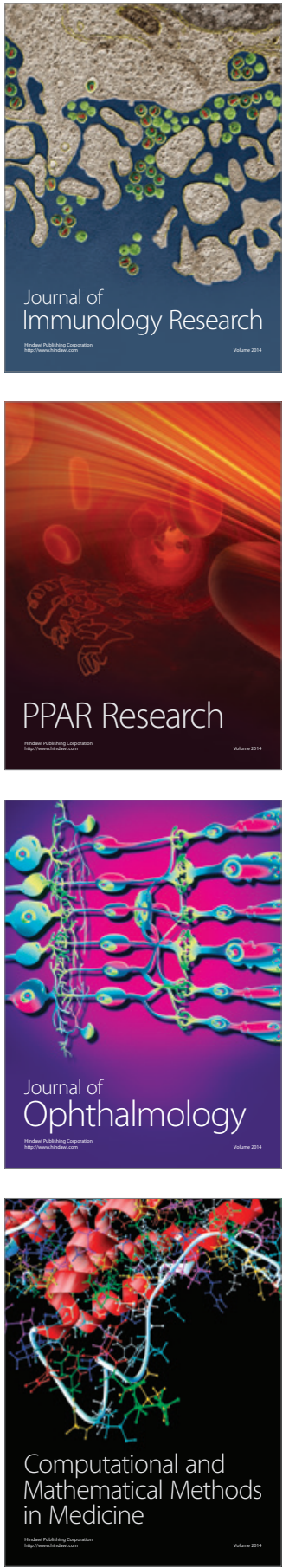

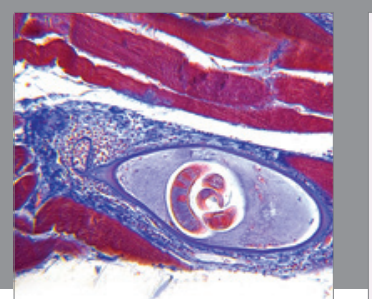

Gastroenterology Research and Practice

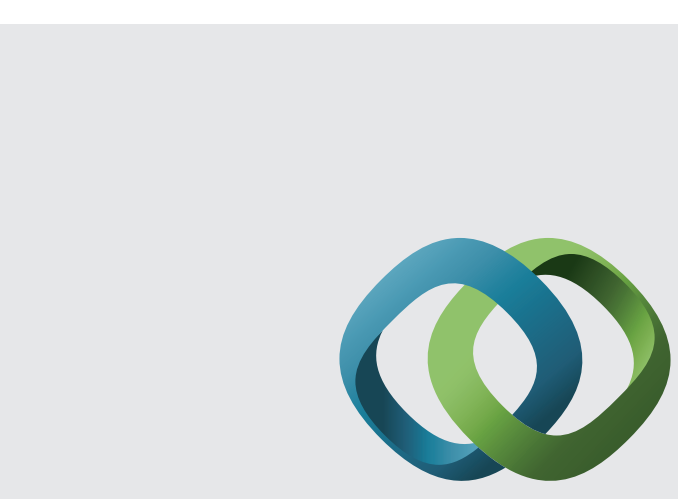

\section{Hindawi}

Submit your manuscripts at

http://www.hindawi.com
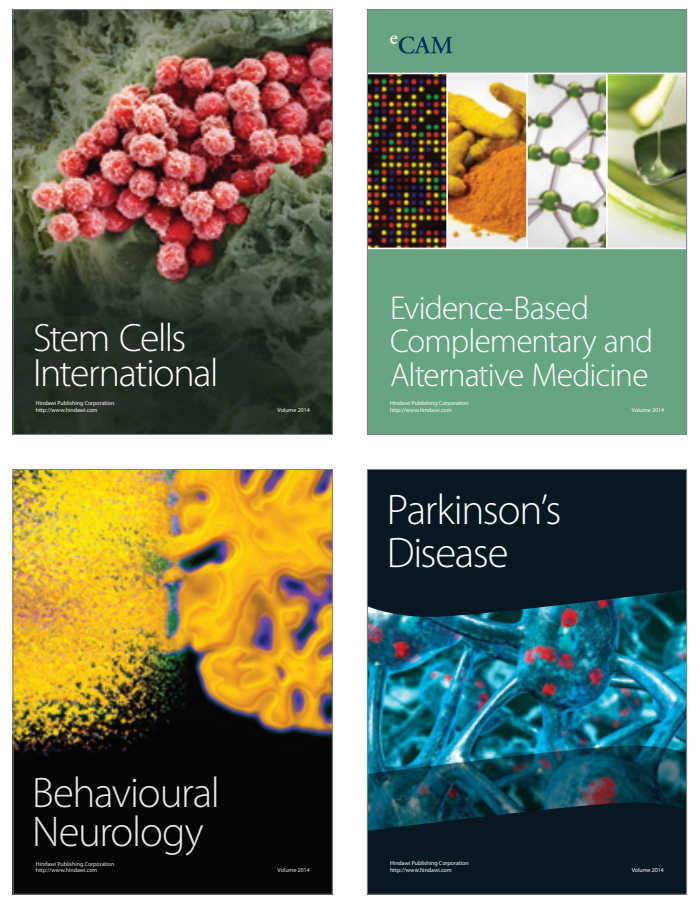
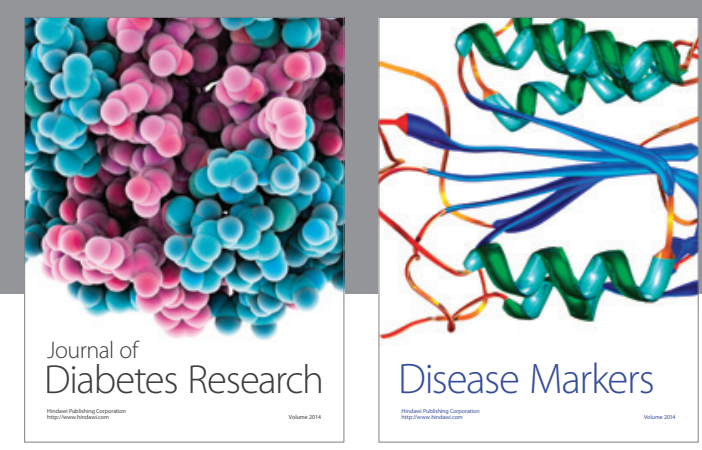

Disease Markers
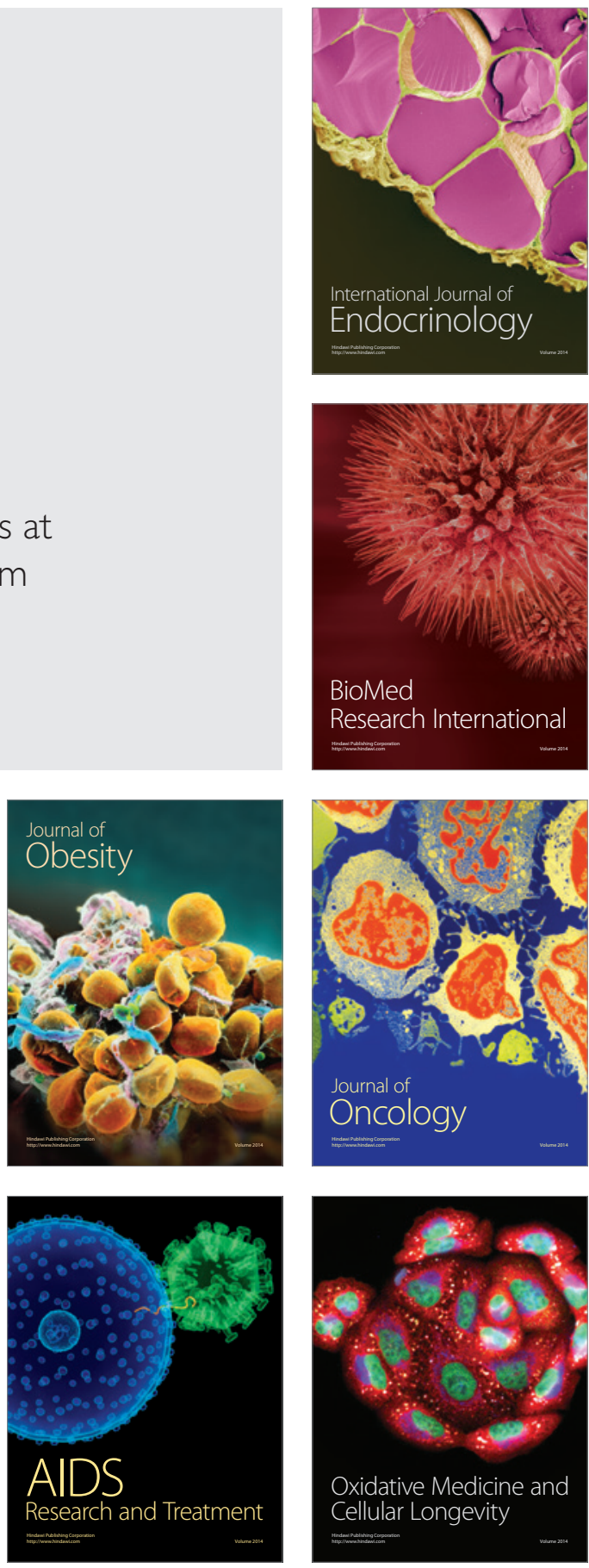